\title{
Design and Test of Fuzzy-PI Controller for Copper Disc Casting Machine Casting Electronic Balance
}

\author{
Fanzhi Kong, ${ }^{1,2}$ Qun Sun, ${ }^{1}$ Chong Wang, ${ }^{1}$ Chengqiang Yin, ${ }^{1}$ and Song $\mathrm{Hu}^{2}$ \\ ${ }^{1}$ School of Mechanical \& Automotive Engineering, Liaocheng University, Shandong, Liaocheng 252059, China \\ ${ }^{2}$ Yanggu Xiangguang Copper Co., Ltd. Shandong, Liaocheng 252327, China \\ Correspondence should be addressed to Qun Sun; sunxiaoqun97@163.com
}

Received 10 August 2014; Revised 13 January 2015; Accepted 14 January 2015

Academic Editor: Massimo Scalia

Copyright (c) 2015 Fanzhi Kong et al. This is an open access article distributed under the Creative Commons Attribution License, which permits unrestricted use, distribution, and reproduction in any medium, provided the original work is properly cited.

\begin{abstract}
Casting electronic scale is the key part of copper casting machine; its control precision directly affects the quality of casting. For this problem, this paper analyzes 16 casting machine casting structures and control principles. According to the movement characteristics of casting, a cast Fuzzy-PI composite controller of electronic scale was designed. On this basis, the hardware system based on PLC and the expansion modules were developed, and casting electronic control programs were designed. Moreover, the control system was simulated by Matlab software and the field experiments have also been carried out. Experiments showed that the casting precision reached $99 \%$, when weight errors are in $3 \mathrm{~kg}$. The designed casting electronic scale satisfies the needs for production.
\end{abstract}

\section{Introduction}

Copper disc casting machine is one of the key equipment components of the copper pyrometallurgical process [1]. Currently, the high end copper disc casting machines of the Chinese copper smelters are mainly imported equipment, such as Outotec products $[1,2]$, and the production price is generally about twice the similar equipment made in China. The electronic scale for casting is a key component of the copper disc casting machine, directly affecting the casting quality. The accuracy of the electronic scale for casting becomes a technical bottleneck restricting domestic products [3].

China Yanggu Xiangguang Copper Co., Ltd., is one of the world's largest copper smelters. In the company's 16-die single copper disc casting machine manufacturing process, a FuzzyPI controller has been designed to provide the electronic scale enhanced casting weight control accuracy.

\section{Structure and Control Principle of a Casting Electronic Scale}

2.1. Structure of a Casting Electronic Scale. A casting electronic scale consists of a casting pan, brackets, electronic scale main body, and an oil cylinder as shown in Figure 1 [3]. The cylinder plunger is raised according to the casting curve, and the copper liquid inside the casting pan is poured into a copper mold. When the casting weight meets the requirements, the cylinder plunger falls rapidly.

During the casting process, the motion of the casting pan can be decomposed into the following operation phases: rapid rising of casting pan $\rightarrow$ slow casting $\rightarrow$ fast casting $\rightarrow$ slow casting $\rightarrow$ constant speed casting $\rightarrow$ fast packing up the casting pan. In the next time the casting process begins, the weight of the set of adjacent anode plates used in the previous casting process is compared with the weight of the plates used in actual casting, and the difference is used as the correction value for the current casting control.

2.2. Casting Control Principle. The weight of the copper liquid in the casting pan is measured by a weighing sensor and a weighing controller, from which the signal is transmitted in real time to the PLC control system. The casting speed is controlled by proportional valves through PLC, which controls the rising and falling of the casting pan. Anode plate weight is obtained by calculating the difference of the copper liquid weight before and after casting. Some factors such as the uncertainties of the casting pan weight during a casting 


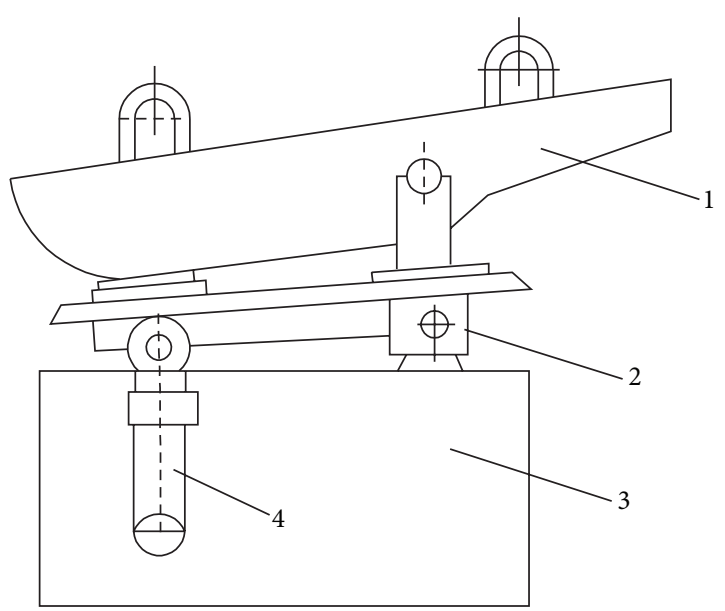

FIgURE 1: The structure of a casting electronic scale. (1) A casting pan, (2) brackets, (3) electronic scale main body, and (4) an oil cylinder.

process, the sensitivity of the electronic scale, and the impact force of pouring copper liquid all affect the precision of the casting weight control.

\section{Design of the Fuzzy-PI Controller}

3.1. Fuzzy-PI Control Principle. The basic schematic of the composite Fuzzy-PI controller is shown in Figure 2 [4-6], where $x(t)$ is the set weight of the copper liquid, $e(t)$ is the difference value between the set value and the measured value, PID is the proportion integration differentiation controller, $K e, K e c$, and $K u$ are used to normalize the weight deviation $e(t)$, the deviation change rate $e^{\prime}(t)$, and control quantity $U$, respectively, FLC is the fuzzy logic controller, switch is the selector used to switch the control model between the PID control and fuzzy control, the threshold of the switch is $280 \mathrm{~kg}$, and $y(t)$ is the measured value of the casting copper weight. The composite controller achieves different control of different states [7-13] through the soft switch between fuzzy and PI controller.

After the input signal $e(t)$, a modal converter is configured with a threshold value, which determines the control mode state using difference between the threshold value and the input signal $e(t)$. When the input $e(t)$ is less than the threshold value, fuzzy control is used through the casting process. If the input $e(t)$ is greater than the threshold value, PI control is automatically switched on to eliminate static error and to enhance the casting speed. The Fuzzy-PI composite controller not only maintains the advantages of the two control modes, but also provides higher steady-state accuracy than a single fuzzy controller and faster dynamic response characteristics than the classical PI controller. Thus it tends to make the system setting faster on the equilibrium point.

Due to poor dynamic performance of one-dimensional fuzzy controller and the complexities of three-dimensional fuzzy controller in terms of long calculation time and programming difficulties, a two-dimensional fuzzy controller was utilized in this study. In fact, as manual control experience indicates, speed control simply from observation of
TABLE 1: Meaning of fuzzy subset $F$.

\begin{tabular}{lcccccc}
\hline Near 0 & Near 1 & Near 2 & Near 3 & Near 4 & Near 5 & Near 6 \\
\hline$Z$ & $V S$ & $S$ & $M S$ & $M$ & $M L$ & $L$ \\
\hline
\end{tabular}

weight will cause large deviations. However, if the rate of weight change is considered and a reasonable control speed is given, good control effects can be achieved. The weight of anode casting plate is $380 \mathrm{~kg}$ and the casting time is about 11 seconds. The anode plate weight deviation $e(t)$ is $0 \sim e(t)_{\max }$, $e(t)_{\max }=W$, where $W$ is the threshold of the Fuzzy-PI controller.

\subsection{Design Procedures of the Fuzzy-PI Controller}

3.2.1. Fuzzy Processing of the Input. During casting, if the system detects relatively large errors, it expects the casting pan to have a higher casting speed to meet the time requirements. Otherwise, if the system detects that the errors are small then it is desirable to slow down the casting speed in order to meet the accuracy claim. After comprehensive comparison and analysis, fuzzy control was only used for the last $100 \mathrm{~kg}$ of casting, whilst PI control was utilized for those before the last $100 \mathrm{~kg}$ [3], in order to meet the rapid casting requirements. The weight deviation $e$, deviation change rate $e c$, and control variable $u$ were divided into subcontinuous variables within (0-6) categories, and then these exact continuous variables were converted into discrete variables in 7 categories. Each category corresponds to a fuzzy subset, respectively, labeled as $Z, V S, S, M S, M, M B$, and $B$, as shown in Table 1 for the specific meanings.

The basic system deviation $e$ is within domain $\left[0, e_{\max }\right]$, where $e_{\max }$ is chosen between $[80,120]$. This study takes $e_{\max }$ as 100 , transformed into a discrete domain $[0,1,2,3,4,5,6]$, and the quantization factor of deviation $e$ is $K e=3 / 50$. The deviation change rate $e c$ is transformed into discrete domain $[0,1,2,3,4,5,6]$, basic domain $[0,70]$, and quantization factor of ec is $K e c=6 / 70$. As the control variable $u$ is transformed into discrete domain $[0,1,2,3,4,5,6]$, the basic domain $[0,3]$, the scale factor of $u$ is 2 . Linguistic variables $E, E C$, and $U$ choose seven language values $[Z, V S, S, M S, M, M L, L]$. When the deviation is nonfuzzy variable, dichotomy method was used to create fuzzy variables. At the same time, values higher than 0.4 were classified as category 1 and those less than 0.4 were classified as category 0 . Then define membership variable $\mu$, and the membership functions of control quantities $E, E C$, and $U$ are shown in Table 2.

Triangular membership functions were adopted due to good sensitivities. Matlab software simulation was carried out, and the membership functions of weight deviation $E$, deviation change rate $E C$, and control quantity $U$ are shown in graph in Figures 3(a), 3(b), and 3(c).

3.2.2. Establish a Fuzzy Rule Table. According to the theory of fuzzy control, a prepared fuzzy control rule table was stored in the PLC, and then the corresponding output variables were 


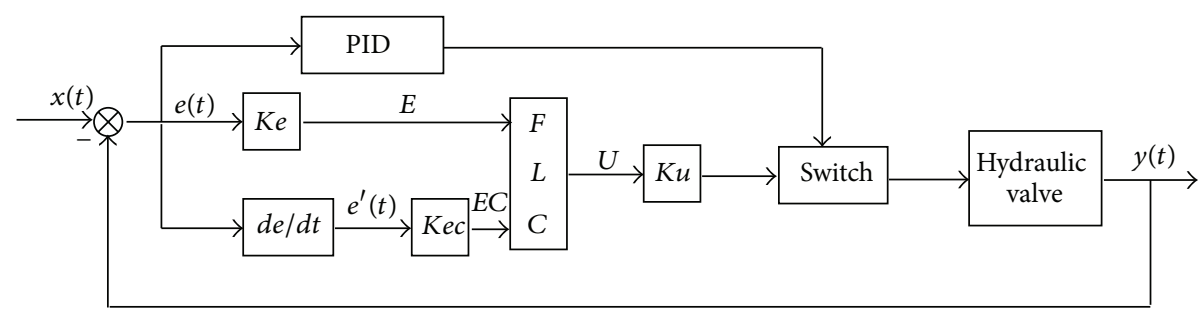

FIgURE 2: The basic schematic of the composite Fuzzy-PI controller.

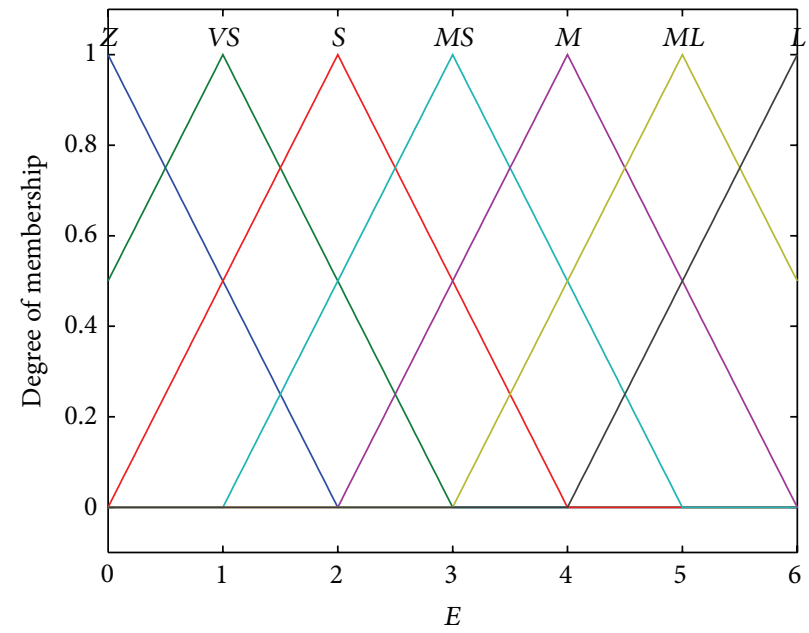

(a) The membership functions of weight deviation $E$

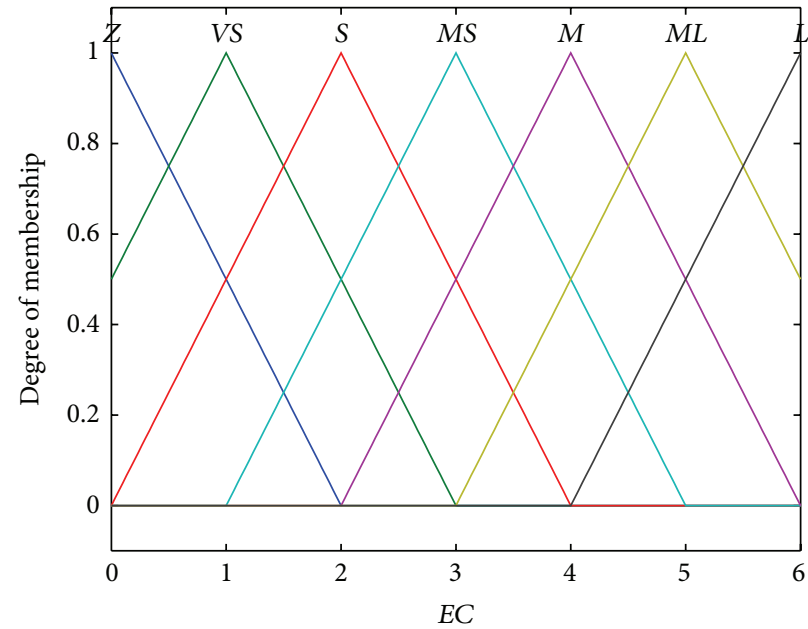

(b) The membership functions of deviation change rate $E C$

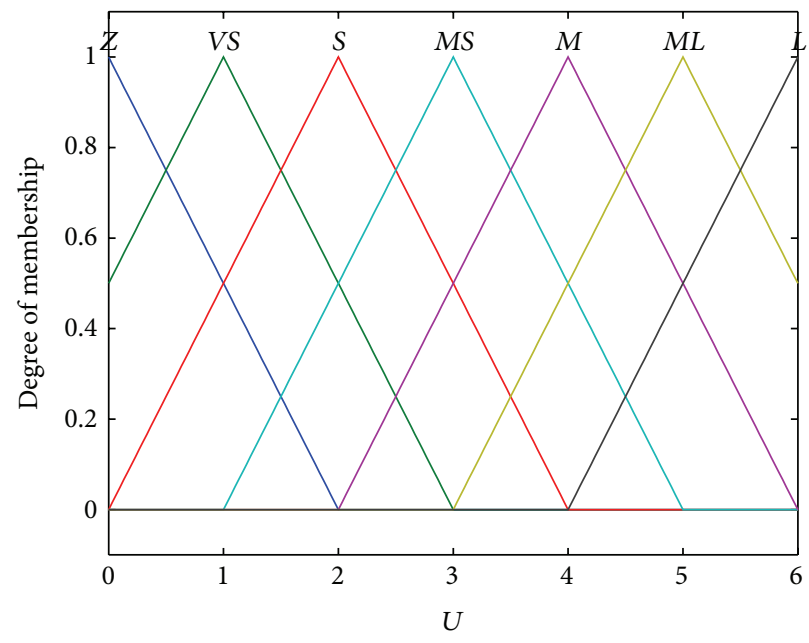

(c) The membership functions of control quantity $U$

FIGURE 3: The membership functions.

obtained based on quantitative input look-up table. The fuzzy rule table is as shown in Table 3.

3.2.3. Fuzzy Reasoning. Fuzzy control algorithm has multiple forms, and, after comprehensive consideration, this paper adopts Mandani fuzzy reasoning rules, such as if $E=A_{i}$ and $E C=B_{j}$ then $U=C_{i j}$; there is a fuzzy relation $R$, as shown below

$$
R=\bigcup_{i j} A_{i} \times B_{j} \times C_{i j}
$$

The specific method to obtain $R$ is as follows. Firstly, let $A_{i} \times B_{i}$ and obtain the matrix rows denoted by $r_{i}$. Secondly, acquire the corresponding vector $C_{i j}$ from the membership function assignment in Table 2 and let $R_{k}=r_{k} \times C_{i j}$. Finally, get the fuzzy relations as shown below:

$$
R=\bigvee_{k=1}^{49} R_{k}
$$




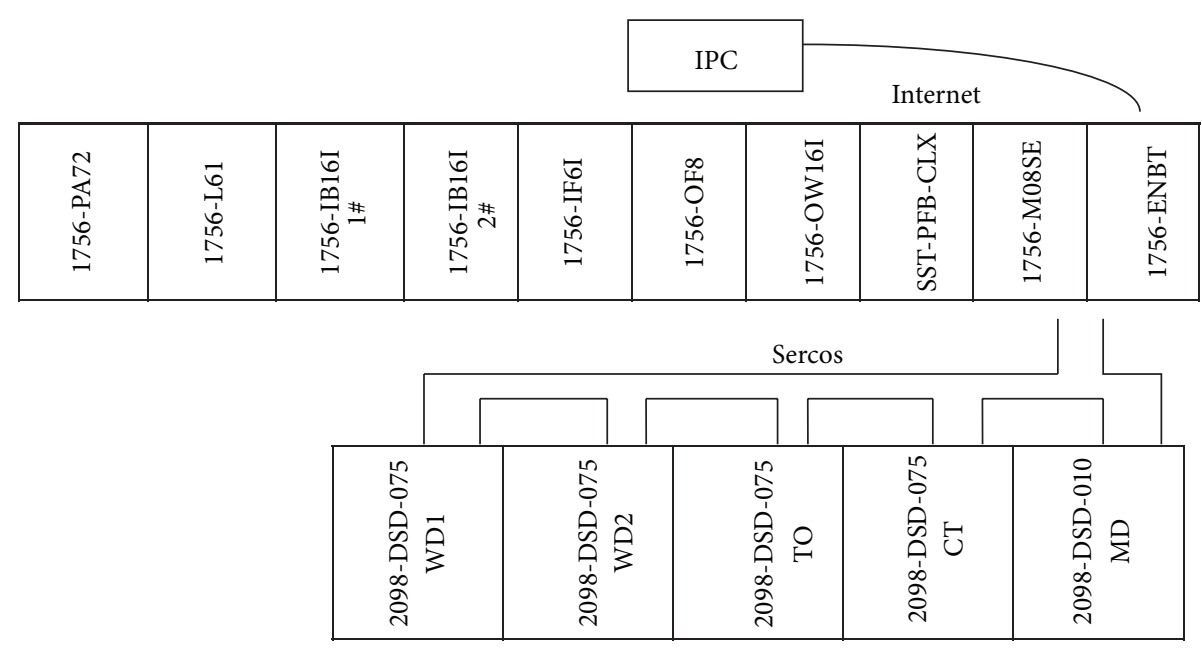

FIgURE 4: The configuration of the PLC controller and connected servo controllers.

TABLE 2: The membership functions of control quantities $E, E C$, and $U$.

\begin{tabular}{|c|c|c|c|c|c|c|c|c|c|}
\hline \multicolumn{3}{|c|}{$\mu$} & \multicolumn{7}{|c|}{$F$} \\
\hline$E$ & $E C$ & $U$ & $Z$ & $V S$ & $S$ & MS & $M$ & $M L$ & $L$ \\
\hline & 0 & & 1 & 0.4 & 0 & 0 & 0 & 0 & 0 \\
\hline & 1 & & 0.4 & 1 & 0.4 & 0 & 0 & 0 & 0 \\
\hline & 2 & & 0 & 0.4 & 1 & 0.4 & 0 & 0 & 0 \\
\hline & 3 & & 0 & 0 & 0.4 & 1 & 0.4 & 0 & 0 \\
\hline & 4 & & 0 & 0 & 0 & 0.4 & 1 & 0.4 & 0 \\
\hline & 5 & & 0 & 0 & 0 & 0 & 0.4 & 1 & 0.4 \\
\hline & 6 & & 0 & 0 & 0 & 0 & 0 & 0.4 & 1 \\
\hline
\end{tabular}

TABLE 3: The fuzzy rule table.

\begin{tabular}{lccccccc}
\hline$U$ & & & \multicolumn{5}{c}{$E$} \\
$E C$ & $Z$ & $V S$ & $S$ & $M S$ & $M$ & $M L$ & $L$ \\
\hline$Z$ & $Z$ & $V S$ & $M S$ & $M$ & $L$ & $L$ & $L$ \\
$V S$ & $Z$ & $V S$ & $M S$ & $M$ & $M L$ & $L$ & $L$ \\
$S$ & $Z$ & $V S$ & $S$ & $M S$ & $M$ & $M L$ & $L$ \\
$M S$ & $Z$ & $V S$ & $S$ & $M S$ & $M$ & $M L$ & $M L$ \\
$M$ & $Z$ & $V S$ & $V S$ & $S$ & $M S$ & $M L$ & $M L$ \\
$M L$ & $Z$ & $V S$ & $V S$ & $S$ & $M S$ & $M S$ & $M$ \\
$L$ & $Z$ & $V S$ & $V S$ & $V S$ & $S$ & $M S$ & $M$ \\
\hline
\end{tabular}

Then use the known $A_{i}, B_{j}$ to solve the corresponding $U$ :

$$
U=\left(A_{i} \times B_{j}\right) \cdot R
$$

Weighted average method is needed to solve fuzzy equations and convert the fuzzy variables into analog outputs, as shown in the following equation, where $\mu_{C j}\left(u_{j}\right)$ is the membership function value of the control quantity; it means the degree of membership to the domain of the control quantity:

$$
u^{*}=\frac{\sum_{j=1}^{n} u_{j} \mu_{C j}\left(u_{j}\right)}{\sum_{j=1}^{n} \mu_{C j}\left(u_{j}\right)} .
$$

In general, as shown in

$$
u^{*}=\frac{\sum_{j=1}^{n} u_{j} k_{j}}{\sum_{j=1}^{n} k_{j}},
$$

$k_{j}$ is the weighted coefficient and $u_{j}$ means each symmetric membership centroid degree function.

3.3. Design of the Fuzzy-PI Controller. The casting pan weighting mechanism is equipped with 3 PR6211 load cells, whose measured voltage signals are sent to a Sartorius weighting controller. The weighting controller transmits 4$20 \mathrm{~mA}$ signal output to the AB-1756 PLC controller. The PLC controller controls the hydraulic proportional valves and solenoid valves, to achieve control of the casting weight.

Figure 4 shows the configuration of the PLC controller and connected servo controllers, including PLC power supply module 1756-A2, ControlLogix controller 1756-L61, 1031 VDC isolation 16p input module 1756-IB16I, analog input module 1756-IF6I, analog output module 1756-OF6CI, digital output module 1756-OW16I, ProfiBus-DP module, 1756M08SE module, and Ethernet module 1756-ENBT.

For the intermediate pack and casting pan control, three operating modes were designed to control casting, including manual, semiautomatic, and fully automatic. Manual means manual control of both the intermediate pack and casting pan; semiautomatic refers to manual operation of intermediate pack but automatic control of the casting pan; fully automatic indicates that both are fully automated casting. The flowchart of the weighing electronic scale quantitative casting control program is shown in Figure 5, and the flowchart for Fuzzy-PI control algorithm is shown in Figure 6 [3].

\section{Simulation}

The reference model of the controlled object is $4 /(S+4)$. The simulation model diagram of the control system established in this study is shown in Figure 7, where the control mode state is implemented by the feedback of the value of $y(t)$. 


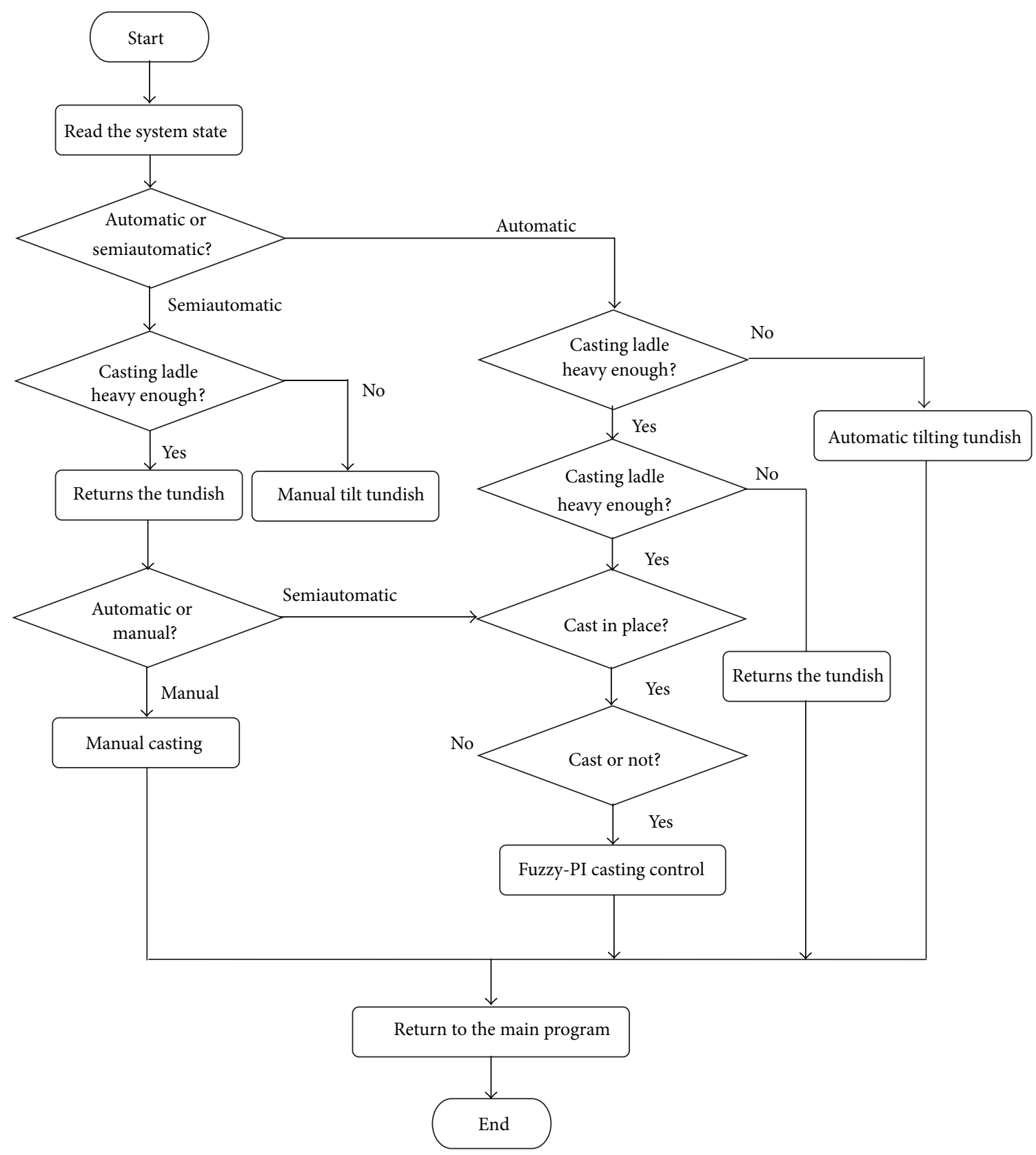

FIGURE 5: The flowchart of the weighing electronic scale quantitative casting control program.

By adding a unit step change to the set point input at $t=0$, the simulation results are shown in Figure 8. A square signal is added to the set point input at $t=0$; the system responses are provided in Figure 9.

It can be observed from the figures that the control action responses of the two modes are all steady, and the control action responses of Fuzzy-PI composite controller are faster than the classical PI controller.

Since the time for continuous casting is generally about 12 seconds, the simulation was carried out for 15 seconds. From the simulation results, the control system was relatively stable and without overshoot and effectively suppressed the external disturbance and enhanced the casting stability. The Matlab simulation diagram for the control output $U$ is shown in Figure 10.

\section{Experiment}

After the preliminary testing, the whole system was running smoothly and security was guaranteed, and actual trial production started. Figure 11 shows the control interface of the copper disc casting machine.

The first test casting produced totally 110 blocks, with an average weight $383.42 \mathrm{~kg}$. Manual casting was only used once when the casting process began, and the weight deviation reached a level exceeding $10 \mathrm{~kg}$. All the other trails were 


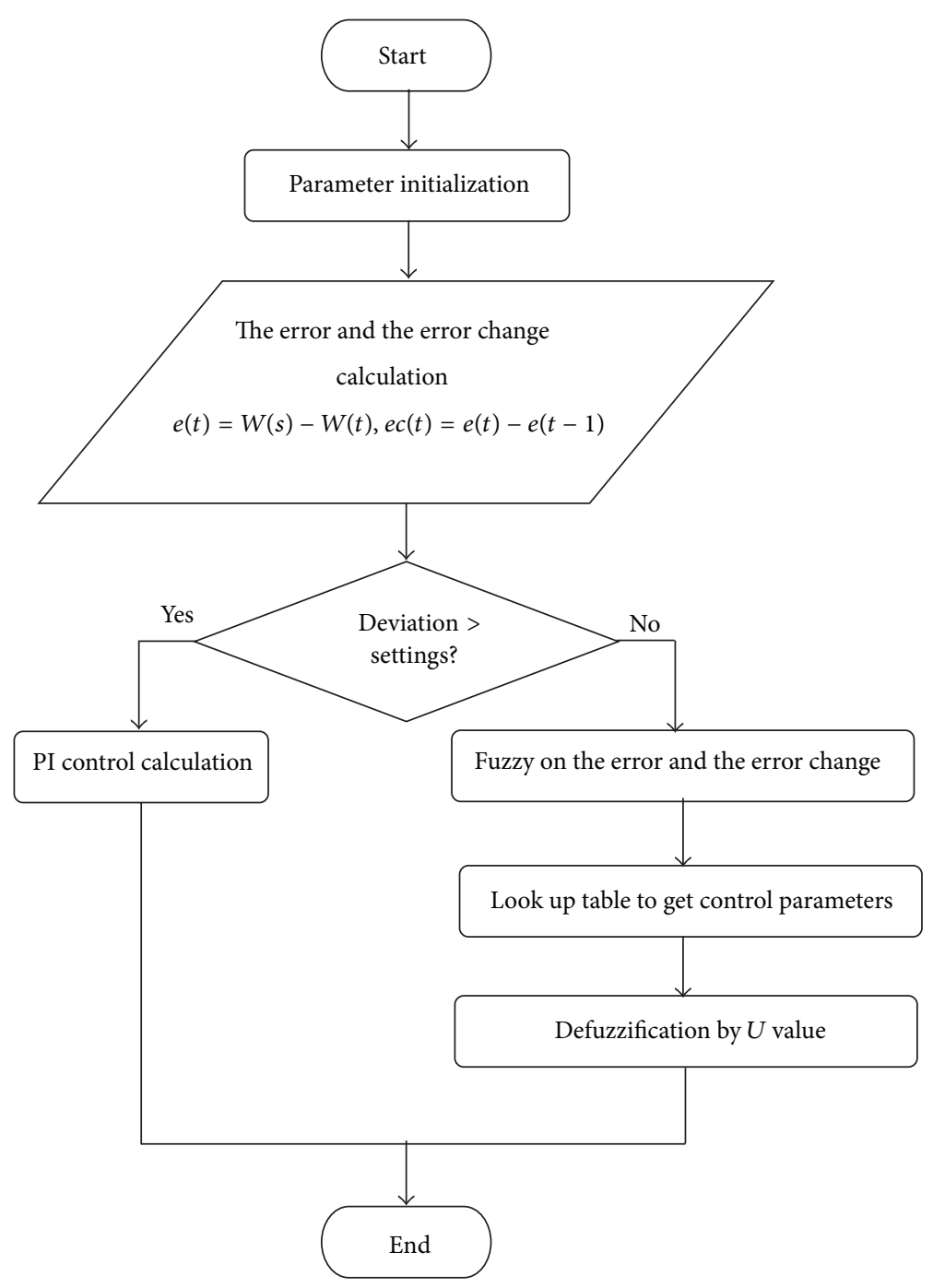

FIgURE 6: The flowchart for Fuzzy-PI control algorithm.

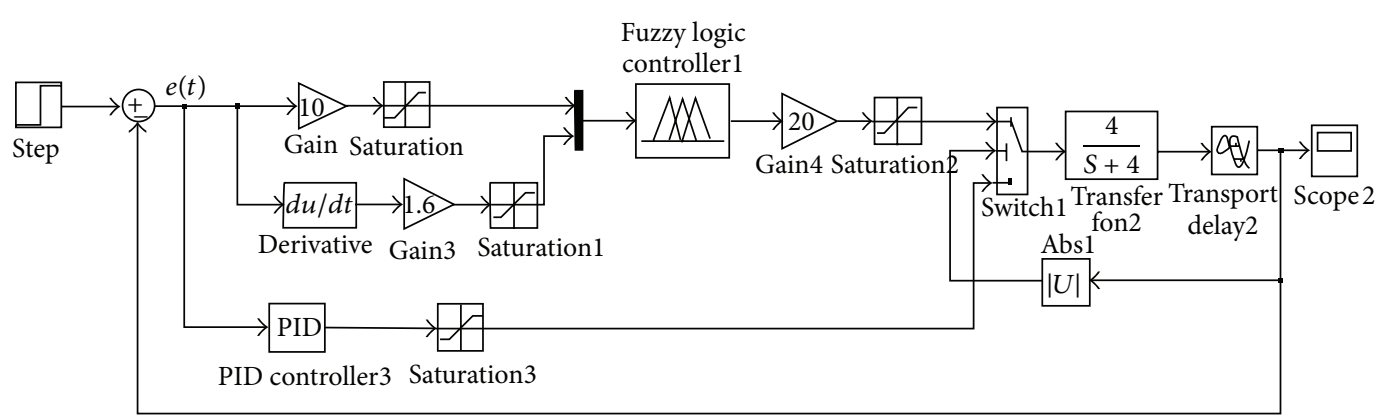

FIGURE 7: The fuzzy system simulation diagram.

automatic casting and there are 13 blocks that have errors greater than $4 \mathrm{~kg}$. There are totally 96 blocks that have qualified weight; that is, the weight error of qualified anode plate should be within $5 \mathrm{~kg}$. Excluding manual casting, the pass rate is $88.07 \%$. The produced anode plates have smooth surfaces and the gradients meet the requirements, without flash or burr. Continue tracking and debugging the control system, adjusting the casting curve; the later casting results are shown in Table 4.

From Table 4 it can be seen that since manual control is largely affected by human factors, such as the experience of the operators, the weight distribution is very uneven. 


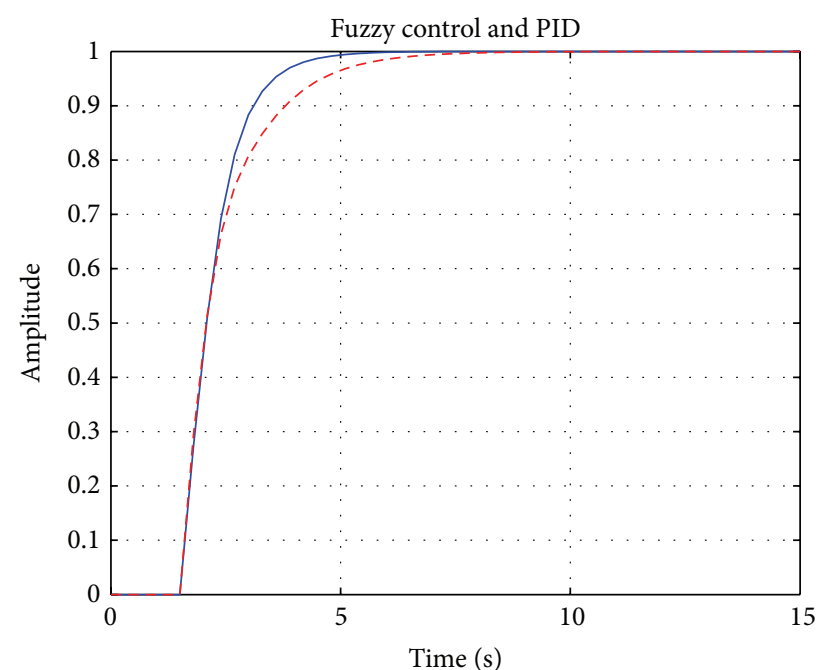

- Fuzzy-PID

--- PID

FIGURE 8: System responses to step signal.

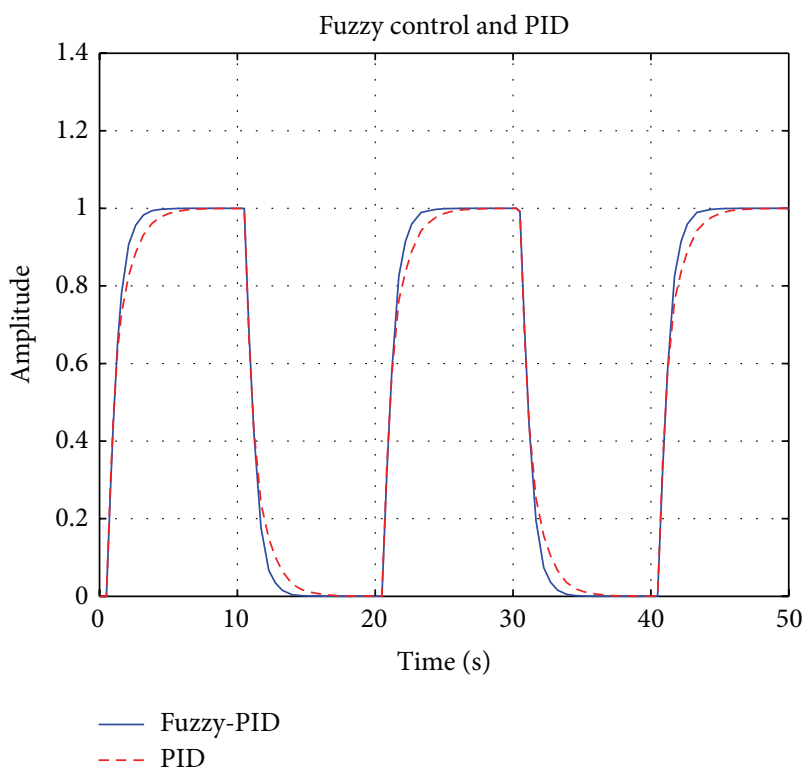

FIGURE 9: System responses to square signal.

Automatic casting produced 504 plates with a pass rate of 99\%.

Furthermore, use a copper disc casting machine manufactured by a Chinese company, and compare the casting experiments; the statistical results of the first 12 casts are shown in Table 5.

Besides, the Outotec copper disc casting machine was used to perform random casting and test results comparison; the data are shown in Table 6.

From Tables 5 and 6 it can be seen that the pass rate of the machine produced by a Chinese company is relatively low, without exceeding 90 percent pass rate after 12 trails. After continuously testing 42 times, only in 10 times, the casting

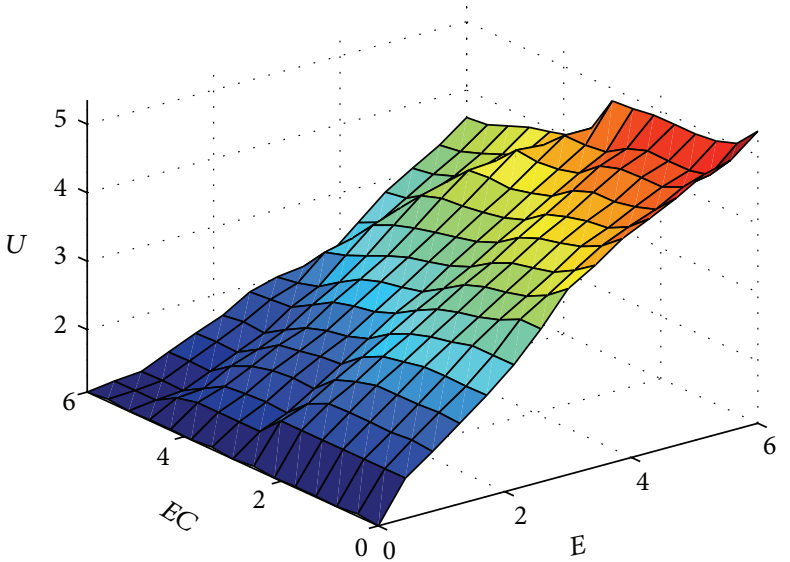

FIGURE 10: The Matlab simulation diagram for the control output $U$.

TABLE 4: The later casting results.

\begin{tabular}{lccc}
\hline Group & Weight errors & Automatic casting & Manual casting \\
\hline 1 & $>+10$ & 1 & 0 \\
2 & +10 & 0 & 0 \\
3 & +5 & 1 & 1 \\
4 & +4 & 3 & 0 \\
5 & +3 & 7 & 0 \\
6 & +2 & 18 & 0 \\
7 & +1 & 61 & 0 \\
8 & 0 & 345 & 0 \\
9 & -1 & 37 & 1 \\
10 & -2 & 19 & 0 \\
11 & -3 & 7 & 0 \\
12 & -4 & 3 & 0 \\
13 & -5 & 1 & 0 \\
14 & -10 & 1 & 1 \\
15 & $<-10$ & 0 & 0 \\
\hline
\end{tabular}

TABLE 5: The casting results of the casting machine made in a Chinese company.

\begin{tabular}{lccc}
\hline Group & Casting numbers & Pass numbers & Pass rate (\%) \\
\hline 1 & 91 & 31 & 34.07 \\
2 & 158 & 93 & 58.86 \\
3 & 152 & 57 & 37.50 \\
4 & 311 & 185 & 59.49 \\
5 & 190 & 122 & 64.21 \\
6 & 203 & 178 & 87.68 \\
7 & 220 & 164 & 74.55 \\
8 & 281 & 251 & 89.32 \\
9 & 338 & 249 & 73.67 \\
10 & 314 & 258 & 82.17 \\
11 & 267 & 218 & 81.65 \\
12 & 330 & 262 & 79.39 \\
\hline
\end{tabular}




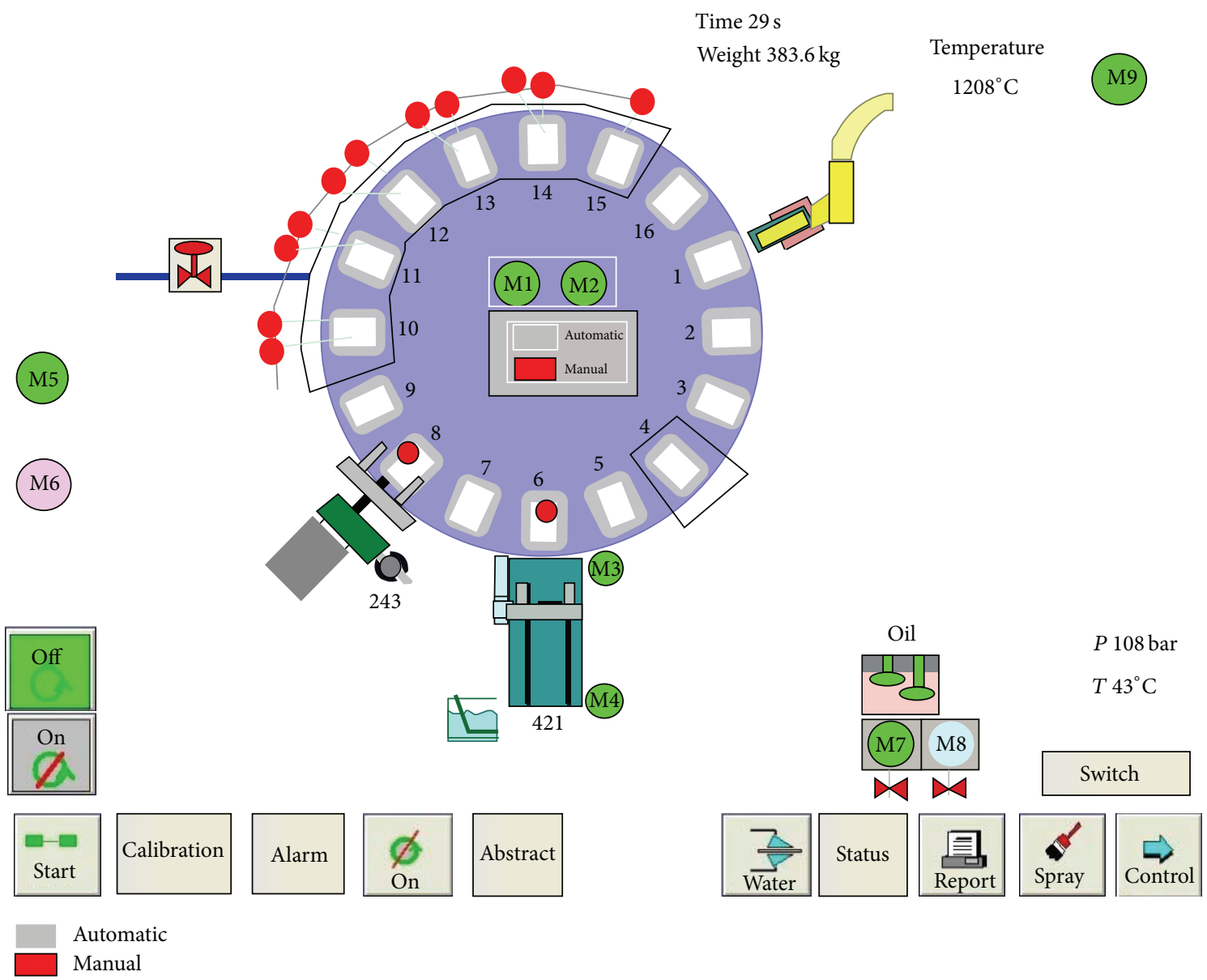

FIgURE 11: The control interface of the control system.

TABLE 6: The casting results of the Outotec casting machine.

\begin{tabular}{lccc}
\hline Group & Casting numbers & Pass numbers & Pass rate $(\%)$ \\
\hline 1 & 71 & 69 & 97.18 \\
2 & 84 & 80 & 95.24 \\
3 & 48 & 44 & 91.67 \\
4 & 40 & 36 & 90.00 \\
5 & 167 & 163 & 97.60 \\
6 & 212 & 197 & 92.92 \\
7 & 505 & 492 & 97.43 \\
\hline
\end{tabular}

results are greater than the 90 percent pass rate. The copper disc casting machine made by Outotec always exhibits a pass rate higher than $90 \%$, and the average pass rate is $94.58 \%$.

\section{Conclusion}

Based on the analysis of the structure and control principle of the electronic scale used for copper disc casting machine, according to the characteristics of the casting, a composite Fuzzy-PI controller has been designed. The hardware system based on PLC and expansion modules have been designed and the control programs have been written. Both Matlab simulation and field experiments have been carried out, which indicated a casting pass rate of $99 \%$, thus satisfying the production requirements.

\section{Conflict of Interests}

The authors declare that there is no conflict of interests regarding the publication of this paper.

\section{Acknowledgments}

This work was supported by the Natural Science Foundation of Shandong Province, China (Grant no. ZR2012CQ026), and a Project of Shandong Province Higher Educational Science and Technology Program (Grant no. J12LB63).

\section{References}

[1] The International Copper Study Group (ICSG), Copper: Preliminary Data for September 2013, ICSG, Outotec, Lisbon, Portugal, 2013, http://www.outotec.com/en/About-us/History/.

[2] Outotec, Anode Casting Technology, Outotec, Puolikkotie, Finland, 2011.

[3] L. Xiaohua, Control Systems of M18 Single Wheel Copper Casting Machine, Central South University, Changsha, China, 2011. 
[4] J. Fei, K. Ma, S. Zhang, W. Yan, and Z. Yuan, "Adaptive current control with PI-fuzzy compound controller for shunt active power filter," Mathematical Problems in Engineering, vol. 2013, Article ID 546842, 11 pages, 2013.

[5] S. Du and C. Zuo, "Self-adaptive fuzzy PI control in energy distribution of pure electric vehicle with dual-energy storage system," International Journal of Control and Automation, vol. 7, no. 3, pp. 283-298, 2014.

[6] A. M. Yazdani, M. A. Movahed, and S. Mahmoudzadeh, "Applying a novel fuzzy-PI controller on the model of continuous stirred tank reactor," International Journal of Machine Learning and Computing, vol. 1, no. 2, pp. 218-223, 2011.

[7] M. T. Jelodar, H. Rastegar, and H. A. Abyaneh, “Turbo expander driven induction generator power quality improvement using fuzzy-PI controlled STATCOM," Journal of American Science, vol. 9, no. 16, pp. 528-536, 2013.

[8] D. Nandan and P. Rai, "A case study on design and evaluation of modified adaptive fuzzy PID controller," Journal of Global Research in Computer Science, vol. 2, no. 12, pp. 51-56, 2011.

[9] R. Coteli, B. Dandil, and A. Fikret, "Fuzzy-PI current controlled D-STATCOM," Gazi University Journal of Science, vol. 24, no. 1, pp. 91-99, 2011.

[10] M. Rosyadi, S. M. Muyeen, R. Takahashi, and J. Tamura, "FuzzyPI controller design for PM wind generator to improve fault ride through of wind farm," International Journal of Renewable Energy Research, vol. 3, no. 2, pp. 308-314, 2013.

[11] W. Dwiono, "Fuzzy PI controllers performance on boost converter," International Journal of Electrical and Computer Engineering, vol. 3, no. 2, pp. 215-220, 2013.

[12] N. Mendes, P. Neto, J. N. Pires, and A. Loureiro, "An optimal fuzzy-PI force/motion controller to increase industrial robot autonomy," International Journal of Advanced Manufacturing Technology, vol. 68, no. 1-4, pp. 435-441, 2013.

[13] A. A. Aly, A. S. Abo El-Lail, K. A. Shoush, and F. A. Salem, "Intelligent PI fuzzy control of an electro-hydraulic manipulator," International Journal of Intelligent Systems and Applications, vol. 4, no. 7, pp. 43-49, 2012. 


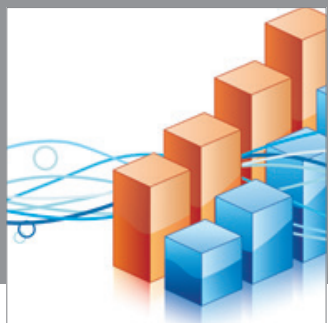

Advances in

Operations Research

mansans

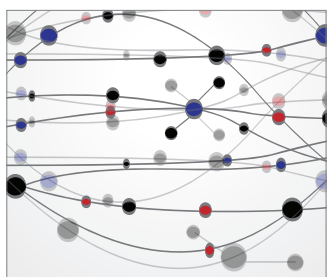

The Scientific World Journal
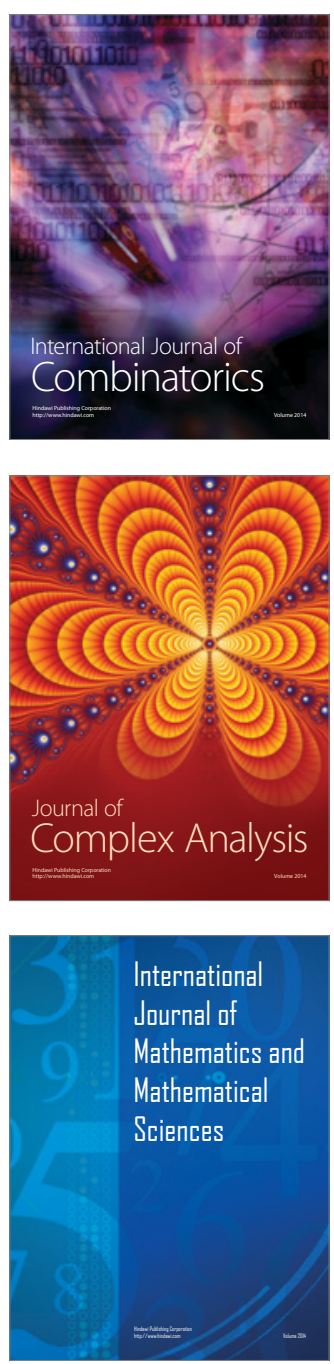
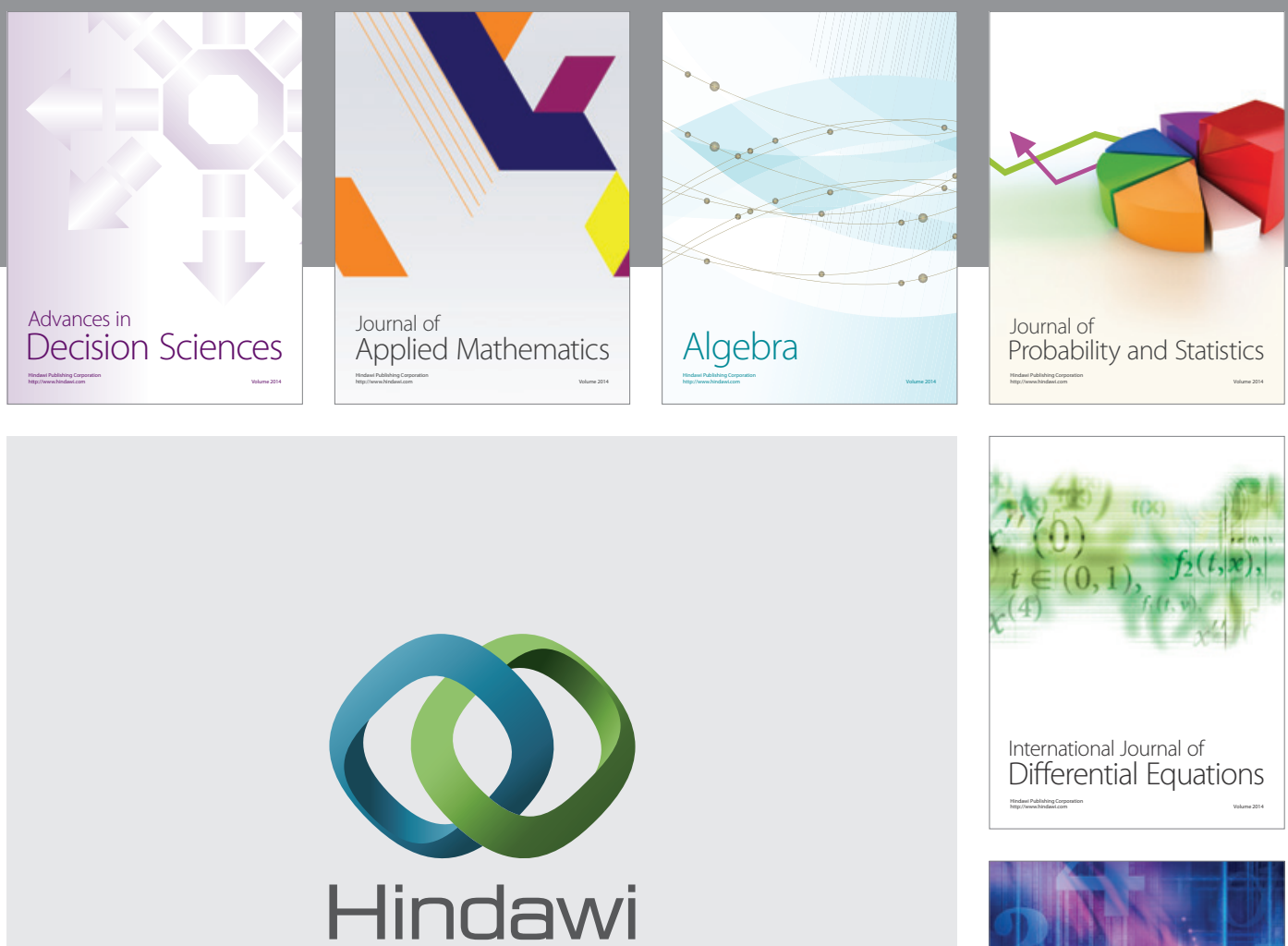

Submit your manuscripts at http://www.hindawi.com
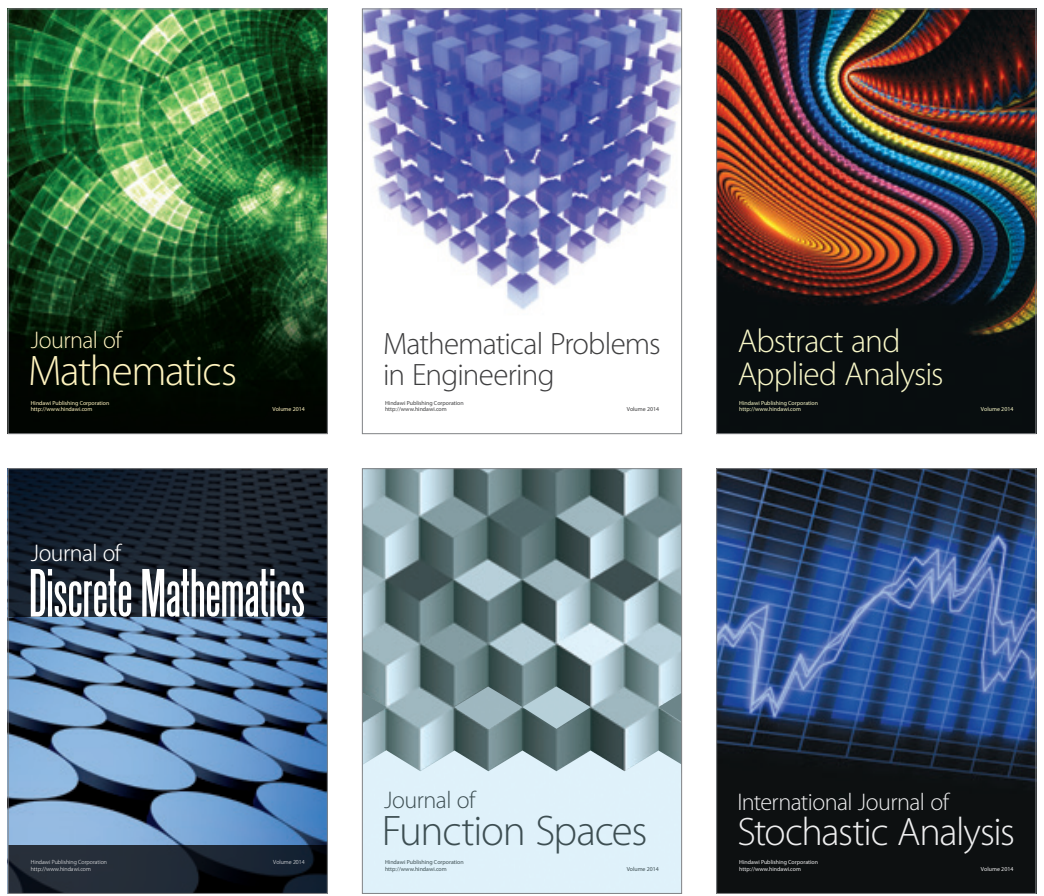

Journal of

Function Spaces

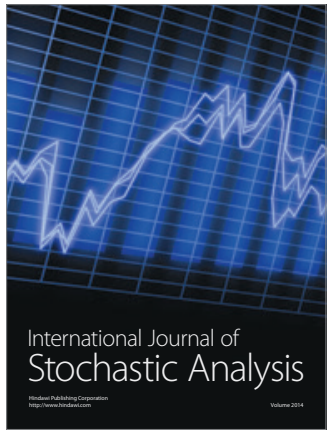

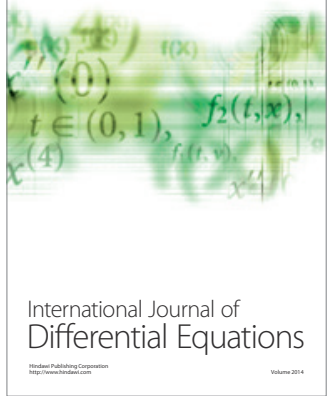
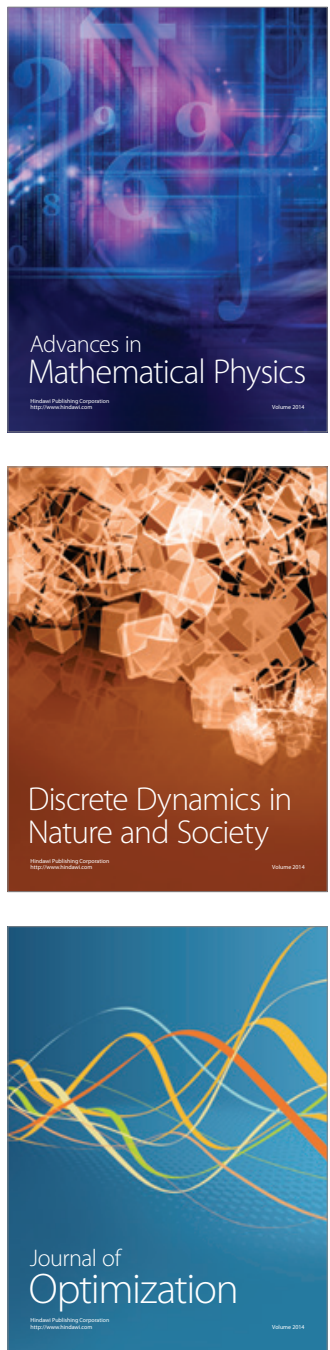